\title{
On Fire Ignition
}

\author{
A. CARLOS FERNANDEZ-PELLO \\ Department of Mechanical Engineering \\ University of California at Berkeley \\ Berkeley, CA 94720 USA
}

\begin{abstract}
A large number of studies have been conducted on the subject of fuel ignition, reflecting the importance of ignition on the onset of fire. However most of the studies are conducted independently for either gaseous, liquid or solid fuels in spite that flaming ignition occurs in the gas phase for all fuels. In this work an attempt is made to present a unified view of the mechanisms leading to the ignition of fuels. The fact that flaming ignition is a gas phase process and that the combustion process that occurs in the gas phase is basically common for all materials. Consequently the mechanisms leading to gas phase ignition can be viewed as the anchoring mechanism for the ignition of any combustible material. The perceived difference in the ignition of gaseous and liquid or solid fuels is associated with processes related to the material gasification, and with minor differences in the process of gas phase ignition. The objective of this work is to provide a more comprehensive view of the process of ignition of gaseous and condensed fuels leading to a better understanding of the different flammability classifications and tests methods used to characterize ignition of different fuels. The ignition of a gaseous fuel is analyzed first, followed by the analysis of the particular characteristics of the ignition of liquid and solid fuels. Clearly, the differences are mostly of material gasification, either liquid evaporation or solid pyrolysis. Moreover, the different test methods used to determine the ignition characteristics of condensed fuels are based on determining the conditions in the condensed phase associated with the gas phase ignition not with the gas phase ignition itself. Although this approach is sufficient for practical purposes, ignoring the gas phase ignition can lead to incorrect conclusions related to material safety.
\end{abstract}

KEYWORDS: ignition, gas, liquid, solid.

\section{NOMENCLATURE LISTING}

\begin{tabular}{|c|c|c|c|}
\hline$c$ & specific heat $(\mathrm{kJ} / \mathrm{kg} \cdot \mathrm{K})$ & $R$ & gas constant $(\mathrm{kJ} / \mathrm{mol} \cdot \mathrm{K})$ \\
\hline$\dot{m}^{\prime \prime}$ & mass flux $\left(\mathrm{kg} / \mathrm{m}^{2} \cdot \mathrm{s}\right)$ & $U$ & characteristic velocity $(\mathrm{m} / \mathrm{s})$ \\
\hline$h$ & enthalpy $(\mathrm{J} / \mathrm{kg})$ & $T$ & temperature $(\mathrm{K})$ \\
\hline$k$ & thermal conductivity $(\mathrm{W} / \mathrm{m} \cdot \mathrm{K})$ & $X$ & mole fraction (-) \\
\hline$l$ & liquid depth (m) & $Y$ & mass fraction (-) \\
\hline $\mathrm{p}$ & pressure $(\mathrm{kPa})$ & $Z$ & pre-exponential factor $\left(\mathrm{s}^{-1}\right)$ \\
\hline$\dot{q}^{\prime \prime}$ & heat flux $\left(\mathrm{kJ} / \mathrm{m}^{2} \cdot \mathrm{s}\right)$ & \multicolumn{2}{|c|}{ Greek } \\
\hline$\dot{r}^{\prime \prime \prime}$ & reaction rate $\left(\mathrm{kg} / \mathrm{m}^{3} \cdot \mathrm{s}\right)$ & $\delta$ & thickness (m) \\
\hline$t$ & time $(\mathrm{s})$ & $\varepsilon$ & emissivity (-) \\
\hline$u$ & velocity $(\mathrm{m} / \mathrm{s})$ & $\rho$ & density $\left(\mathrm{kg} / \mathrm{m}^{3}\right)$ \\
\hline$A$ & area $\left(\mathrm{m}^{2}\right)$ & $\dot{\omega}^{\prime \prime \prime}$ & gasification/pyrolysis rate $\left(\mathrm{kg} / \mathrm{m}^{3} \cdot \mathrm{s}\right)$ \\
\hline$B$ & mass transfer number & \multicolumn{2}{|c|}{ subscripts } \\
\hline$E$ & activation energy $(\mathrm{kJ} / \mathrm{mol})$ & $\infty / 0$ & ambient \\
\hline$F$ & fuel & con & convective \\
\hline$H$ & heat transfer coefficient $\left(\mathrm{W} / \mathrm{m}^{2} \cdot \mathrm{K}\right)$ & che & chemical \\
\hline$H c$ & non-dimensional heat of combustion & diff & diffusion \\
\hline$L v$ & heat of vaporization $(\mathrm{kJ} / \mathrm{kg})$ & ext & external \\
\hline$Q c$ & heat of combustion $(\mathrm{kJ} / \mathrm{kg})$ & fuel & fuel \\
\hline \multirow[t]{2}{*}{$\dot{Q}_{\text {rad }}^{\prime \prime \prime}$} & radiant heat flux $\left(\mathrm{kJ} / \mathrm{m}^{2} \cdot \mathrm{s}\right)$ & $g$ & gas \\
\hline & & $i g$ & ignition \\
\hline
\end{tabular}




\section{INTRODUCTION}

Fire encompasses a wide variety of combustion processes ranging from smoldering and glowing combustion to explosion and detonation. However fire is normally associated with the combustion of a combustible material resulting in the release of heat and flames. Also, fires are more often associated with the burning of solid and liquid fuels than with gaseous fuels although the later also cause fires. The ignition of fire is the phenomenon leading to the establishment of the fire. In most cases the combustion of the fuel occurs in the gas phase, and the differences in behavior between condensed and gaseous fuels depend more on the process of material gasification than in that of flaming combustion. Thus classifying a fire depending on whether the fuel is solid, liquid or gas is more a material issue than a combustion one. Furthermore, this classification has given way to definitions of basically the same combustion process in different ways depending on the type of fuel. This is particularly true when analyzing the ignition of a condensed material leading to fire.

The flaming ignition of a fuel is obviously a critical process in the initial development of a fire. It determines the ease of fire initiation in a given scenario and the materials that may be involved in the fire. It must be recognized however that without the subsequent propagation of the flames throughout the fuel, ignition may be inconsequential. Because of its importance in the onset of fire, ignition has been studied intensively. The ignition of a gaseous fuel has been studied primarily in the context of the combustion of fuels for power generation, heating or explosion prevention. There are many books in combustion that review gaseous fuel ignition, examples are Refs. [1-4]. Related to fire ignition, the studies focus more on condensed fuels. There are excellent reviews published on condensed fuel ignition. Particularly notable is the compendium of works on the subject of fuel ignition of Babrauskas [5]. There are also reviews that address specific subjects of the ignition process of condensed fuels [6-12]. Thus there is not a need for another review on the subject, except perhaps for some specific aspects of fire ignition such as that of smoldering ignition. However this author feels that there is a need to clarify certain aspects of the ignition of fire particularly when addressing flaming ignition, and the differences in the processes leading to the ignition of condensed versus gaseous fuels. Particularly important is the realization that flaming is a gas phase combustion process and that the differences in behavior between condensed and gaseous fuels depends more on the process of material gasification than in that of combustion. Furthermore, there is also a need to clarify the definition of flaming ignition since the definition of a flaming fire is not well defined by itself. For example, a flame is often misrepresented as a well defined entity, while in reality a flame is a region where a combustion reaction takes place, and as such it may have very different characteristics. In particular the heat release rate or luminosity depend on a number of factors such as whether the gaseous fuel and oxidizer are premixed or not, the ratio of fuel-to-air, the sooting properties of the fuel, etc.. Thus, there is a need to first define what is understood as flaming ignition and then characterize it based on its definition.

This work attempts to provide first a definition of fire ignition based on the phenomena leading to the onset of flaming combustion. Then, it also attempts to provide a unified view of the ignition of different fuels using the combustion process that occurs in the gas phase as the unifying mechanism, and associating the differences with the processes related to the material gasification. The objective is to provide a more comprehensive view of the process of ignition of gaseous and condensed fuels leading to a better understanding of the different flammability classifications and test methods for the different fuels. First the ignition of a gaseous fuel is analyzed and presented as the anchoring point for fire ignition of any material. Then the particular characteristics of the ignition of liquid and solid fuels are analyzed and shown to be mostly of material gasification.

\section{GAS PHASE IGNITION}

Ignition is defined here as the process leading to the onset of a sustained gas phase reaction (flame) in a combustible gaseous mixture of a fuel and an oxidizer. As it will be shown below, for a combustion reaction to be initiated, the temperature of the combustible mixture must be elevated above a certain value at least within a volume equivalent to the flame volume. For the combustion reaction to be sustained the heat released by the reaction must be larger than the heat lost from the reaction to its surrounding. Thus the onset of ignition could occur by increasing locally the combustible mixture temperature with an external heat source (spark, pilot flame, hot surface), and the sustained ignition of the combustible mixture could 
occur by ensuring that the temperature of the mixture remains high. Thus the ignition of a combustible gaseous mixture is basically the initiation of a combustion reaction between the fuel and oxidizer followed by the establishment of the reaction through a balance between the energy generated by the combustion reaction and the heat lost from the reaction to the surrounding. This applies both to spontaneous ignition and piloted ignition, the difference being the localized application of a heat source in the later case and the uniform heating of the mixture in the former. Mathematically this balance can be expressed by the energy equation, written below in its differential and lumped formulations (the complete formulation of the problem would require the mass and momentum conservation equations [1]):

Differential

$\rho c_{p} \frac{\partial T}{\partial t}=-\rho u c_{p} \frac{\partial T}{\partial x}+k \frac{\partial^{2} T}{\partial x^{2}}-\dot{Q}_{r a d}^{\prime \prime \prime}+\dot{r}_{f u e l}^{\prime \prime \prime} Q_{c}$

Lumped

$\frac{d(\rho V h)}{d t}=\int_{A}\left(\dot{m}^{\prime \prime} h\right) d A+\int_{A} \dot{q}^{\prime \prime} d A-\int_{V} \dot{Q}_{r a d}^{\prime \prime \prime} d V+\int_{V} \dot{r}_{f u e l}^{\prime \prime \prime} Q_{c} d V$

Similar equations can be developed for the conservation of momentum and the transport of species in and out of the reaction zone and their consumption or production (species energy conservation). This is not done here for brevity since we are concentrating on the thermal aspects of the ignition process. In the above equations the left hand term indicates the variation of the enthalpy of the fuel/oxidizer mixture being considered, the first term on the right hand the flow of energy in and out of the system control volume, the second term the heat losses from the volume of mixture to the surrounding, and the third the rate of heat released by the combustion reaction of the mixture. Mathematically, ignition is initially determined by stating that the time rate of change of enthalpy (or temperature) must be positive. This is because as the temperature of the reaction region increases the heat released by the reaction also increases which leads to an eventual thermal runaway and the establishment of a vigorous reaction. In the case of piloted ignition the heat generation term is assisted by an external heat source of a volume generally much smaller than that of the overall mixture. In the case of spontaneous ignition the volume heated is that of the whole mixture. The initiation of the combustion reaction is a necessary condition for ignition, but not sufficient. For a sustained ignition to occur ignition must be followed by a premixed flame propagating through the mixture, and/or the establishment of a diffusion flame.

The rate of heat release term in Eqs. 1 and 2 contains the product of two important parameters in combustion: the heat of combustion (or heating value) of the fuel, and the rate at which the reaction is progressing. The heating value, as well as the maximum temperature that the products of combustion can reach, are controlled by the thermodynamics of energy conversion between the reactants and products. The dependence of these two parameters on the fuel/air ratio is presented in Fig. 1, which shows that the heat released by burning the fuel is constant for lean mixtures (excess oxidizer) because all the fuel is consumed but decreases for rich mixtures (excess fuel) because there is not enough air to burn the fuel. The products temperature, or combustion temperature, has a maximum at stoichiometric conditions (fuel-to-oxygen ratio for complete combustion) and decreases for leaner mixtures (more air to be heated) and rich mixtures (less fuel burnt). 


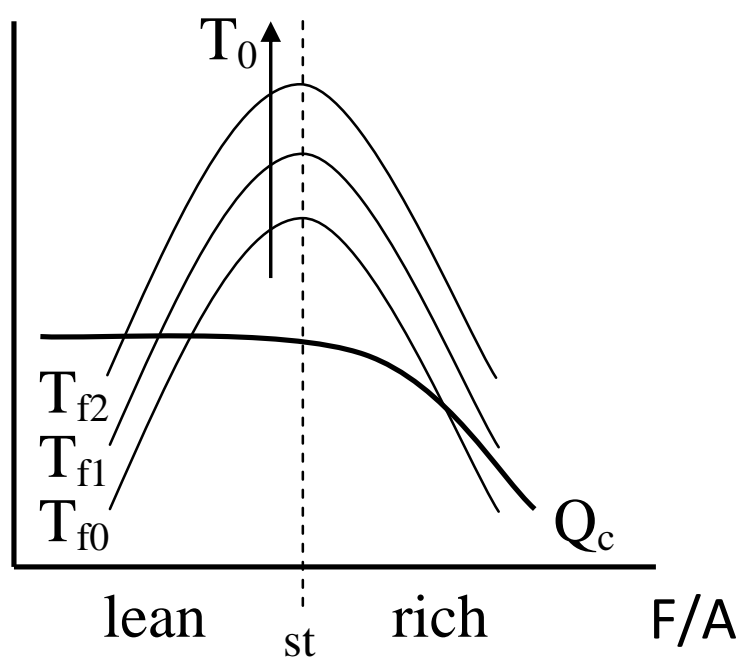

Fig. 1. Dependence of the heat release and flame temperature on the fuel/air ratio.

The mathematical determination of the rate of the reaction can be quite complex depending on the complexity of the fuel and the intermediate reaction that occur during its oxidation. However, in a global form it can be expressed by an equation of the form (Arrhenius reaction rate):

$$
\dot{r}_{\text {fuel }}^{\prime \prime \prime} Q_{c}=\rho\left[O_{2}\right]^{n_{O_{2}}}[F]^{n_{F}} A \exp \left(-\frac{E}{R T}\right) Q_{c}
$$

The important things to observe are the strong dependence on temperature of the reaction rate through the exponential function, its dependence on the mole fractions of fuel and oxidizer, and the dependence on pressure through the species concentrations. The dependence of the reaction rate on temperature is shown schematically in Fig. 2, where the reaction rate is generally small until a certain temperature is reached at which point the reaction rate increases very fast with temperature. This temperature determines a large increase on the reaction term of Eq. 1 or 2 and consequently a likely increase in the temperature gradient in the left hand side of the equation. Thus, this temperature, or a temperature around this region (inflexion point for example), could be defined as a threshold temperature for the reaction to occur and consequently as an 'ignition temperature'. However, there are a number of factors that affect the energy balance in Eqs. 1 and 2 so the concept of an ignition temperature must be accepted with caution, and only as an approximate value necessary for ignition to occur. It should be pointed out that the existence of a threshold temperature for ignition can also be supported from the chemical reactions that take place during the combustion of the fuel. The different elementary chemical reactions that take place in a combustion reaction are carried out primarily by the presence of radicals $(\mathrm{OH}, \mathrm{H}, \mathrm{O})$, and it can be argued that a minimum temperature must be reached for the radicals to be formed. In this work we will concentrate on the thermal aspects of the combustion process. 


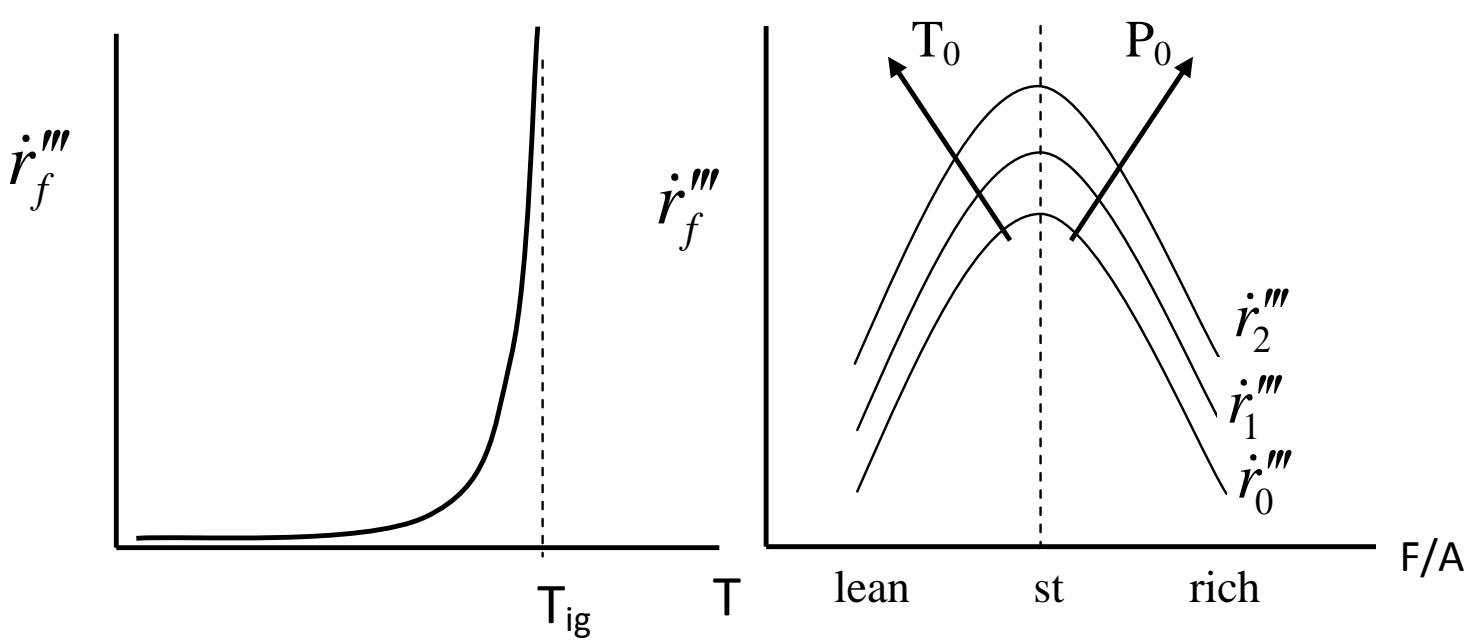

Fig. 2. Dependence of the reaction rate on temperature and the fuel/air ratio.

Another important aspect of the reaction rate characteristics is that since the combustion temperature depends on the fuel/oxidizer ratio (Fig. 1), consequently so does the reaction rate. This dependence is shown schematically in Fig. 2, where the combustion temperature and reaction rates are maximum at stoichiometric conditions, decreasing as the mixture becomes either rich or lean, faster toward the lean limit that the rich limit.

From Eqs. 1 and 2 it is seen that for the time rate of change of the mixture temperature to be positive, i.e., for potential ignition to occur, the heat produced by the reaction must be larger than the heat losses to the environment. In spontaneous combustion, the burning of a significant amount of fuel is being considered. It is normally assumed that the temperature of the mixture is increased gradually until the heat release term becomes larger than the heat loss term. From then on the mixture temperature increases continuously in an acceleratory fashion until a temperature runaway takes place, which is normally considered as ignition. In piloted ignition the mixture is heated locally by a spark, flame or hot spot, so that a small amount of fuel mixture is ignited near the heating source. This energy is normally small (of the order of mJ) although as pointed out below it depends on the mixture stoichiometry and ambient conditions. If the localized ignition is followed by the propagation of a flame through the mixture, ignition is normally considered to occur. Although both spontaneous and piloted ignition have many common characteristics, here we will address only piloted ignition.

The existence of a localized ignition does not guarantee the establishment of sustained ignition, or flaming ignition. This will be determined by whether a propagating premixed flame, or the subsequent generation of a non-premixed (diffusion) flame, are established after the localized ignition. The transition from a localized ignition source to a propagating premixed flame or to the eventual establishment of a diffusion flame is complex [13], and beyond the scope of this paper. However, a lumped formulation as in Eq. 2 can be used to determine if a premixed flame will propagate through the combustible mixture once ignition has occurred and to calculate the velocity of propagation of a flame. This is done by balancing the heat generated in the reaction with the heat required to heat the mixture to the flame temperature as the flame propagates through the mixture. Such a simplified balance provides an expression for the laminar flame speed of the form [1-4]

$V_{F}=\left(\alpha \frac{Q_{c} \dot{r}_{F}^{\prime \prime \prime} / \rho-\dot{Q}_{r a d}^{\prime \prime \prime}}{c_{p}\left(T_{i g}-T_{0}\right)}\right)^{1 / 2}$

It is seen that the flame speed is approximately proportional to the square root of the reaction rate, and consequently has many of the dependences that the reaction rate has. Equation 2 can also be used to determine the thickness of the reaction zone (flame), and it is found that the flame thickness is inversely proportional to the flame speed [1-4]. The resulting dependence of the flame speed on the mixture 
characteristics is shown schematically in Fig. 3. The results of Fig. 3 have important implications not only from the point of view of fire initiation but also in fire safety, such as heat release rates, flame arrestor diameter, etc. Those related to ignition will be addressed below.

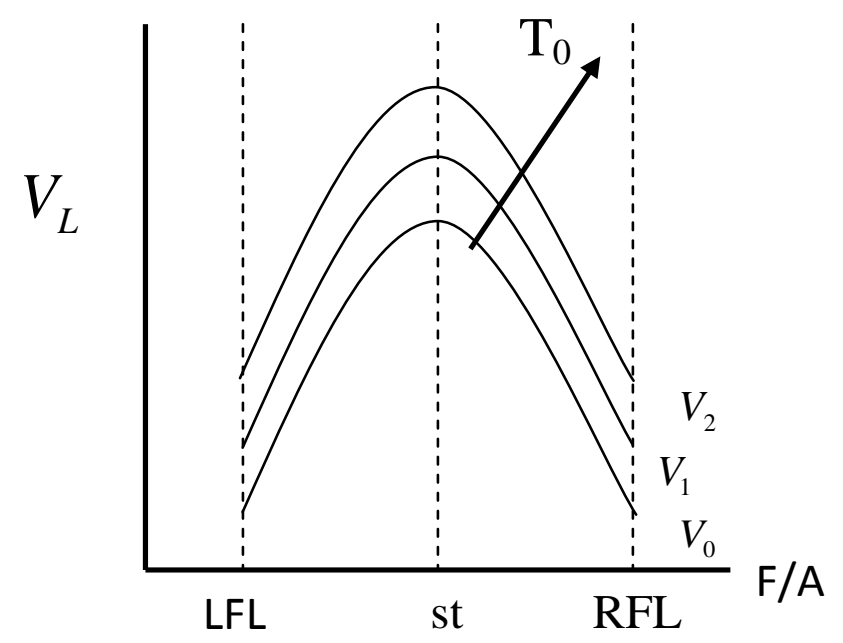

Fig. 3. Dependence of the flame speed on the fuel/air ratio.

An important aspect of the energy balance in Eqs. 1 and 2, and the relation for the flame speed of Eq. 4 is that since as the mixture becomes lean or rich, the reaction rate decreases, there is a point that the rate of heat release is too low to overcome the heat losses to the surrounding and to sustain flame propagation. These limiting conditions determine the flammability limits of the fuel: the lean flammability limit (LFL) at the lean side of the curve below which the mixture cannot ignite and sustain flame propagation; and the rich flammability limit (RFL) at the rich side of the curve beyond which the fuel cannot ignite either. These limits are sometimes called the explosive limits, although there are some differences depending on the application. If the fuel/oxidizer ratio is within the flammability limits, the mixture is flammable and can ignite if the conditions are appropriate for flame propagation. If the mixture is below the LFL or above the RFL, then it is not flammable and ignition cannot occur. From Eqs. 1 to 4 it is seen that the ambient temperature, the ambient oxygen concentration and pressure affects these limits by increasing the reaction rate as they increase. However, since the flammability limits are determined not only by ignition of the mixture, but also by the propagation of a flame through the mixture, the dependence of the flammability limits on these parameters is more complex than those extracted from Eqs. 1 to 3. In fact the LFL is not dependent on oxygen concentration, only the RFL is, because at lean conditions all the fuel is consumed and consequently the heat released is independent of the oxygen concentration and thermal properties of nitrogen and oxygen are very similar. Also because the flame propagation is only weakly dependent on pressure, the flammability limits are also weakly dependent on pressure.

The flammability diagram of a gaseous fuel, and the corresponding fuel-to-air ratio at the flammability limits, have important implications in fire safety. A gaseous fuel, with a large heating value, and with the potential of causing a large fire, can be contained under safe conditions if it is stored beyond its flammability limits. An example is propane in a tank where the mixture is too rich to ignite, or a leak of propane in a well-ventilated area where the mixture is too lean to ignite. Since ignition is often considered from the point of view of the gaseous mixture being initially below the LFL is brought within the flammable limit by a wanted or unwanted increase of the fuel concentration in the mixture, most of the attention has been placed on the LFL. However, there are many occasions when the gaseous mixture is too rich to be flammable but becomes flammable through the dilution with oxygen. An example of this type of ignition is backdraft that occurs when a mixture of combustible gases in a room is too rich to ignite but then becomes flammable by air entrainment after ventilation is introduced (e.g., firefighters open a door). Many building fires become under-ventilated, i.e., above the RFL, as the fire progresses and reignite after an influx of fresh air. 
An important pending issue inherent in Eqs. 1 and 2 is that of how much energy an external source (spark, pilot flame, hot surface, etc.) needs to have to cause ignition. In principle, as mentioned above, bringing the gaseous mixture to the 'ignition temperature' will initiate the combustion process. The volume of combustible needed to be ignited is also in principle small, of the order of the flame thickness (a few $\mathrm{mm}$ ). Then, because the density of most gaseous hydrocarbon/air combustible mixtures is small, the energy required to bring the mixture to the ignition temperature is also small (of the order of $\mathrm{mJ}$ ). However, this energy will increase as the mixture fuel-to-air ratio deviates from stoichiometric conditions, the ambient conditions change (increased pressure, lower oxygen concentration) and particularly as the heat losses to the surroundings increases. For example, the proximity of a cold surface to the ignition source, or air currents in its vicinity, may require a significant amount of energy for ignition or may even prevent ignition. Obviously the closer the mixture to stoichiometric conditions the easier to ignite since the incipient reaction will be stronger (Fig. 2). Finally, as mentioned above, for ignition to be truly established the reaction (flame) must propagate through the mixture.

When solving an ignition problem, it may be necessary to use the differential formulation if a detailed description of the combustion process is attempted. However, its mathematical solution is generally difficult because of the nonlinear character of the reaction term and it may require a numerical solution. One simplifying approach is to non-dimensionalize the corresponding equations and to analyze the different non-dimensional terms that are formed in the process. Comparison of the different terms may lead to simplification of the equations and their solution as described below.

Defining non-dimensional quantities based on the characteristic variables of the problem as

$$
\bar{t}=\frac{t}{\tau}, \quad \bar{x} \equiv \frac{x}{\delta}, \quad \bar{T} \equiv \frac{T}{T_{p}-T_{\infty}}, \quad \bar{u}=\frac{u}{U},
$$

where $\tau$ denotes the characteristic time of the ignition process, $U$ is the characteristic velocity of the problem, $\delta$ the characteristic length of the problem, $T_{F}$ the flame temperature and $T_{\infty}$ the ambient temperature. The non-dimensional formulation of Eq. 1 becomes

$$
\frac{1}{\tau} \frac{\partial \bar{T}}{\partial \bar{t}}=-\frac{U}{\delta} \bar{u} \frac{\partial \bar{T}}{\partial \bar{x}}+\frac{\alpha}{\delta^{2}} \frac{\partial^{2} \bar{T}}{\partial \bar{x}^{2}}-\frac{\dot{Q}_{r a d}^{\prime \prime \prime}}{\rho c_{p}\left(T_{F}-T_{\infty}\right)}+\frac{\dot{r}_{f u e l}^{\prime \prime \prime} Q_{c}}{\rho c_{p}\left(T_{F}-T_{\infty}\right)}
$$

or

$$
\frac{\partial \bar{T}}{\partial \bar{t}}=-\frac{\tau}{\tau_{c o n v}} \bar{u} \frac{\partial \bar{T}}{\partial \bar{x}}+\frac{\tau}{\tau_{\text {diff }}} \frac{\partial^{2} \bar{T}}{\partial \bar{x}^{2}}-\frac{\tau}{\tau_{\text {rad }}}+\frac{\tau}{\tau_{c h e m}} \frac{Q_{c}}{c_{p}\left(T_{F}-T_{\infty}\right)}
$$

where $\tau_{c o n v}=\frac{\delta}{U}$ is the convective time, $\tau_{d i f f}=\frac{\delta^{2}}{\alpha}$ is the diffusion time, $\tau_{r a d}=\frac{c_{p}\left(T_{F}-T_{\infty}\right)}{\dot{Q}_{r a d}^{\prime \prime \prime}}$ is the radiation time and $\tau_{c h e m}=\frac{\rho}{\dot{r}_{\text {fuel }}^{\prime \prime \prime}}$ the chemical time. The characteristic time $\tau$ depends on the controlling mechanism of the combustion process. If diffusion is dominant, as often occurs in fire problems, the characteristic time of the problem will be the diffusion time, $\tau=\tau_{\text {diff }}$, and Eq. 6 would take the form

$$
\frac{\partial \bar{T}}{\partial \bar{t}}=-\frac{\tau_{\text {diff }}}{\tau_{\text {conv }}} \bar{u} \frac{\partial \bar{T}}{\partial \bar{x}}+\frac{\partial^{2} \bar{T}}{\partial \bar{x}^{2}}-\frac{\tau_{\text {diff }}}{\tau_{\text {rad }}}+\frac{\tau_{\text {diff }}}{\tau_{\text {chem }}} H_{c}
$$


In Eq. 7 there are four distinct non-dimensional groups $\frac{\tau_{\text {diff }}}{\tau_{\text {conv }}}=\frac{\alpha}{U \delta}$ which is the inverse Peclet number and that relates diffusion heat transfer to convection energy transport, $\frac{\tau_{d i f f}}{\tau_{r a d}}=\frac{\alpha}{\delta^{2}} \frac{\dot{Q}_{r a d}^{\prime \prime \prime}}{c_{p}\left(T_{F}-T_{\infty}\right)}$ that relates conduction to radiation heat transfer, $H_{c}=\frac{Q_{c}}{c_{p}\left(T_{F}-T_{\infty}\right)}$ which relates the heat of combustion to the heat necessary to rise the gas temperature to the flame temperature and is close to unity, and $\frac{\tau_{\text {diff }}}{\tau_{\text {chem }}}=\frac{\alpha}{\delta^{2}} \frac{\dot{r}_{\text {fuel }}^{\prime \prime \prime}}{\rho}$ which is the diffusion based Damkholer number that relates the chemical time to the diffusion transport time.

Depending on the comparative values of these parameters some of the terms in Eq. 7 can be neglected simplifying the solution of the problem. This is particularly useful in limiting the conditions of heat and mass transport or chemical kinetics. For example if ignition is piloted and the pilot is strong (high temperature and energy), and/or the ambient oxygen concentration is high, then the chemical time will be very short because the reaction rate will be fast. Consequently the reaction term in Eq. 7 will be very large (large Damkholer number) in comparison with the other terms and the can be removed from the equation by keeping the rate of heat released from the reaction. The later is obtained from the rate of species transport to the reaction and the heat of combustion. Consequently the ignition process becomes a heat and mass transport-dominated process and Eq. 7 becomes a transport equation only with the ignition process controlled by the balance between convection and diffusion transport of the reactants toward the pilot location, and the transfer of heat from the pilot to the reactants. As shown below, this is the approach followed when analyzing results from test methods like the cone calorimeter [13] or LIFT [14] apparatus.

Another limiting case of interest is when the Damkholer number is small either because the oxidizer velocity is high (strong air currents or wind) or because the reaction rate is small (vitiated air, low temperature, low pressure), i.e., the characteristic chemical time is small. Selecting the characteristic time of the problem as the convection time, $\tau=\tau_{\text {conv }}$, Eq.6 would take the form

$$
\frac{\partial \bar{T}}{\partial \bar{t}}=-\bar{u} \frac{\partial \bar{T}}{\partial \bar{x}}+\frac{\tau_{c o n v}}{\tau_{\text {diff }}} \frac{\partial^{2} \bar{T}}{\partial \bar{x}^{2}}-\frac{\tau_{c o n v}}{\tau_{\text {rad }}}+\frac{\tau_{\text {conv }}}{\tau_{\text {chem }}} H_{c}
$$

In Eq. 8 there are three distinct groups, $\frac{\tau_{\text {conv }}}{\tau_{\text {diff }}}=\frac{U \delta}{\alpha}$ (Peclet), $\frac{\tau_{\text {conv }}}{\tau_{\text {rad }}}$ that relates convection to radiation heat transfer and $\frac{\tau_{\text {conv }}}{\tau_{\text {chem }}}=\frac{\delta}{U} \frac{\dot{r}_{\text {fuel }}^{\prime \prime \prime}}{\rho}$ which is the convective Damkholer number and relates the chemical time to the convective transport time. If the gas velocity is large the convection time will be small and the conduction and radiation terms can be neglected in Eq. 8. The ignition process becomes a convective transport and reactive controlled process and Eq. 8 becomes a convective reactive equation only with the ignition process controlled by the balance between the rate of convection transport of the reactants toward the pilot location and the reaction rate. Ignition will occur only if the reaction rate is strong enough to overcome the convective heat losses. A graphic example of this case is when one has to protect a match from the wind in order to ignite it. If the ambient oxygen concentration, or pressure, are the parameters being changed, as they are reduced the reaction rate decreases (Eq. 3) and the chemical time increases. Then the ignition process initially transport controlled at elevated pressure becomes more and more controlled by chemical kinetics as the pressure reduces. Eventually the reaction rate would be too small to overcome the heat losses and ignition cannot occur. An example of the behavior of the ignition process as the ambient pressure is varied will be shown later (Fig. 8) with the above limiting regimes of ignition approximately identified. 
Although the above approach of comparing terms as normalized equations to reduce their complexity is very useful, the availability of powerful computers is currently allowing the numerical solution of ignition problems using their full differential formulations. However, keeping the thermo-chemical aspects of the problem in sight is still recommended.

Finally, it should be noted that the above discussed combustion characteristics of a gaseous fuel, including ignition, flame propagation, the establishment of a diffusion flame, and the flammability limits also apply to any liquid or solid fuel that after being heated, is converted into the gaseous state. This is addressed next.

\section{CONDENSED FUEL IGNITION}

The ignition and flaming burning of a condensed fuel occurs in the gas phase through the combustion of the gasified combustible gases with the surrounding oxidizer. Thus, for a condensed fuel to ignite, the fuel must first gasify so that a combustible gaseous mixture is formed by mixing of the fuel vapor with the surrounding oxidizer. Then the conditions for ignition stated above for a gaseous fuel mixture must be met. However, if the condensed fuel has not gasified totally, the gaseous fuel may not be totally mixed with the oxidizer, and/or the interaction of the gaseous mixture with the remaining condensed fuel may affect the characteristics of the ignition and flame propagation processes. These effects may consequently differentiate somewhat the ignition characteristics of gaseous and condensed fuels.

\section{Liquid Fuels}

The evaporation of a liquid fuel in a gaseous oxidizing environment is determined by the thermodynamic properties of the fuel. Particularly useful is the Clausius-Clapeyron relation that relates the evaporation temperature of the liquid with the partial pressure of the fuel vapor next to the liquid/gas interface as:

$$
\ln \left(\frac{P_{2} / P}{P_{1} / P}\right)=\frac{L_{v}}{R}\left(\frac{1}{T_{1}}-\frac{1}{T_{2}}\right)
$$

Equation 9 shows that the evaporation temperature of the liquid depends on the partial pressure of the vapor at the gas/liquid interface, decreasing as the partial pressure decreases. This is important because the fuel properties and environmental conditions (vapor density, ambient temperature, air currents, confinement, etc) will affect the partial pressure and consequently the evaporation temperature of the liquid. In the particular cases where the gases near the liquid surface are near saturation (confined and denser than air vapor, for example) since the partial pressure would be near unity, the evaporation temperature would be close to the saturation temperature. Thus, as a first approximation, it can be said that a fuel that is in liquid state at room temperature and is contained in a confined environment must be heated to near its saturation temperature, or boiling point, before it can ignite. However, the partial pressure of the fuel vapor is affected by the oxidizer flowing over the liquid surface that reduces the partial pressure and consequently the evaporation temperature. Thus in general, care should be taken in relating the boiling point of a liquid with its evaporation temperature, and consequently with its ignition temperature, even before considering gas phase effects.

In order to consider gas phase aspects of liquid fuel ignition, it is necessary to know the rate of fuel gasification and characteristics of the gas phase. The heating of the liquid under an external heat source is given by the energy equation applied to the liquid volume. In 1-D it has the form

$$
\frac{\partial(\rho h)}{\partial t}+\frac{\partial\left(\dot{m}^{\prime \prime} h\right)}{\partial x}=\frac{\partial}{\partial x}\left(k \frac{\partial T}{\partial x}\right)+\dot{\omega}^{\prime \prime \prime} L_{v}
$$

The boundary conditions would indicate the type of heating that the liquid fuel would be subjected to. For a liquid/gas interface heating, either convective or radiative, this boundary condition would be $-k \partial T /\left.\partial x\right|_{x=0}=\dot{q}_{e x t}^{\prime \prime}$. The back-face boundary condition and the initial condition complete the specification of the problem. 
The solution of Eq. 10 is complicated because of the convective term that results from internal buoyant circulation of the liquid. However, assuming that heating of the liquid is uniform due to the internal circulation and considering that many liquid fuels have an elevated thermal conductivity, a lumped-type formulation of Eq. 10 can be used to calculate the time needed to heat the liquid to its evaporation temperature as

$$
t_{i g}=\rho c l \frac{T_{v a p}-T_{0}}{\dot{q}_{e x t}^{\prime \prime}-\dot{q}_{l o s s}^{\prime \prime}}
$$

In the presence of a strong enough pilot the time given by Eq. 11 could be defined as the ignition time of the liquid fuel, since it can be assumed that once the fuel starts vaporizing the pilot would ignite the fuel vapor. However, the presence of gaseous fuel is only a necessary condition for ignition but not a sufficient condition. For ignition to occur a flammable gaseous mixture must be generated near the pilot and it must be ignited. This necessary limiting condition is often defined as 'flashing ignition' because it often appears in the form of flashes as the incipient vaporized fuel is consumed by the combustion reaction. For ignition to be fully established a premixed flame must propagate through the flammable mixture generated above the liquid surface that eventually will generate a persistent diffusion flame over the liquid surface [15]. This condition is determined by the characteristics of the gas next to the liquid fuel surface, and the subsequent ignition mode is normally defined as 'fire ignition'.

The rate of fuel vaporization provides further information about the ignition process in the gas phase. The rate of fuel gasification is obtained by applying the energy equation at the liquid/gas interface. Assuming that the liquid has a uniform temperature at the evaporation temperature, the rate of fuel evaporation is given by the ratio of the rate of heating of the liquid to its heat of evaporation.

$\dot{m}_{v a p}^{\prime \prime}=\frac{\dot{q}_{e x t}^{\prime \prime}}{L_{V}}$

The rate of heating, $\dot{q}_{e x t}^{\prime \prime}$, is more or less complicated although for many practical cases it is a convective and radiative heat flux applied to the gas liquid interface. In case of convective heating only Eq. 12 can be expressed as:

$\dot{m}_{\text {vap }}^{\prime \prime}=\frac{h_{\text {conv }}}{c_{p}} \ln (1+B)$

where the parameter $B$ is often referred to as the ' $B$ ' number [16]. The $B$ number of the fuel is sometimes used to rank the fire risk of the fuel since the larger the $B$ number the larger the rate of fuel evaporation for a given heating rate and consequently the larger the fire risk.

Although the evaporation of the liquid fuel is a necessary condition for ignition to occur, it does not necessarily imply that ignition will occur. For ignition to occur a flammable (within the flammability limits of the fuel) mixture of gaseous fuel and oxidizer must be formed near a heating source capable of igniting the gas. The rate of fuel evaporation needed to attain the flammable mixture will depend on the characteristics of the oxidizer surrounding the liquid (still or flowing oxidizer, pressure, oxygen concentration, etc). Furthermore, if the liquid is evaporating from a pool, such as in a liquid spill, the mixture above the fuel surface is generally not uniform. For most hydrocarbon fuels the vapor density is greater than the air density and if the liquid is spilled on a horizontal surface, as the liquid evaporates, a layer of fuel vapor with a decreasing concentration gradient is formed above the liquid surface [17] (Fig. 4). 


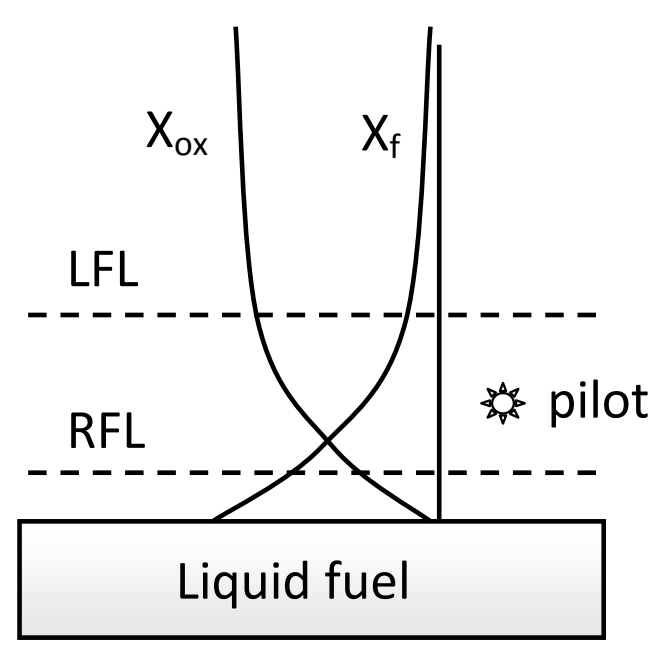

Fig. 4. Fuel and oxidizer distribution above the surface.

The characteristics of this layer for a confined liquid are well described by the Stefan stagnant layer problem [18]. Near the surface the mixture is too rich to ignite and away from the surface too lean to ignite. In between there is a layer where the mixture is within the flammability limits (flammable). Thus, for ignition to occur the pilot must be located within this flammable layer. Unfortunately even this view of the problem is in some cases too simplistic and there are other complicating factors. Typically in an unconfined liquid fuel spill the vapor-spread diameter is greater that the fuel spill diameter and air entrainment rapidly dilutes the fuel layer such that the vapor concentration at the outer limit of the layer is beyond the lean limit, and the flammable layer in the interior is close to the liquid surface. In addition to the heat losses to the surrounding air from the incipient ignition reaction there are heat losses to the liquid surface which impose further restrictions on the ignition of the fuel. In fact if the pilot is within the quench layer above the liquid, ignition will not occur even if the mixture is flammable. Another interesting fact is that if the pilot does not remain in contact with the mixture for a sufficient amount of time, ignition may not occur either. Finally factors such as the flow of oxidizer over the liquid surface, the oxygen concentration and pressure of the ambient oxidizer will change the characteristics and location of the flammable layer and consequently imposes further restrictions about the location of the pilot for ignition to occur.

Therefore, although the conditions for the ignition of a liquid fuel are well understood, the practical determination of the conditions for ignition of a liquid fuel are not so clear. The practical approach is exemplified by the classification of the ignitibility of a liquid fuel by its ignition temperature under a specific protocol like in the Cleveland open cup method [19]. In this method a liquid fuel is placed in a cup and heated slowly until it is ignited by a pilot flame placed above the liquid surface. The liquid temperature at which the first ignition flash is observed is called the 'flash point'. The liquid temperature at which sustained burning is observed is called the 'fire point'. The temperature difference being that needed for a higher rate of gasification to be established in order to obtain sustained combustion in the gas phase.

It is interesting to analyze the attainment of the flash and fire points from the point of view of the gas phase ignition. If the liquid fuel is initially below its evaporation temperature it must be heated until it starts to evaporate. As indicated above, this evaporation temperature will depend on the partial pressure of the fuel vapor above its surface. As the liquid is heated further, the thickness of the layer of decreasing fuel concentration formed above the liquid surface will increase with time. Simultaneously the partial pressure of fuel vapor will increase near the surface and consequently the liquid temperature must be increased for the liquid fuel to continue evaporating. Eventually the LFL is reached at the pilot location and the mixture ignites. It turns out that since heat is lost to the liquid by the incipient reaction, ignition may not occur if the pilot is too close to the surface (within the quenching distance) because of the added heat losses. If the pilot is too far from the liquid surface the fuel layer may not grow to that location and ignition will not occur. The initial ignition of the fuel vapor results in its consumption and if it is not replenished quickly a flash is observed. As the temperature of the liquid is increased and more fuel vapor is produced the flashing intensifies which contributes to the liquid heating and eventually sustained burning occurs. 
The above mechanism assumes a still air layer surrounding the liquid. However, if there is an air flow above the liquid surface, the vapor partial pressure will decrease and consequently the evaporation temperature. This should result in lower ignition temperatures. However, because of the air flow, the rate of fuel gasification must also increase to form a combustible mixture above the liquid, and the fuel vapor layer will also have larger concentration gradients which may require heating the liquid to a higher temperature. This is the reason for the establishment of the Pensky-Martens closed cup testing methods [20] and the differing ignition temperatures that may result in comparison with the Cleveland open cup method. It is worth noting that the differences between the Cleveland open cup method and the Pensky-Martens closed cup method appear in Eq. 11 through the evaporation temperature, $T_{v a p}$, and heat loss, $\dot{q}_{l o s s}^{\prime \prime}$, parameters.

Variations in the oxidizer flow conditions are not the only reason to obtain differing liquid fuel ignition temperatures. The ambient pressure is another important factor because since the density of the oxidizer would be different, the amount of fuel vapor needed to reach the LFL would also be different. For example, in locations at high altitude where there are lower ambient pressures the liquid fuel evaporates at lower temperatures (Eq. 9) and since the air density would be lower, less fuel would be needed to reach a flammable mixture and to attain ignition. Consequently in reduced ambient pressures the open cup method would give a lower flash and fire points.

So far we have considered the case where the liquid fuel has a boiling point above the ambient temperature and consequently must be heated to ignite. There are liquid fuels however that have boiling points below the normal ambient temperature. In those cases ignition can always occur except if the mixture above the liquid is outside the fuel flammability limits, in which case ignition cannot occur. If the liquid fuel is enclosed, the gaseous mixture above the liquid would normally become too rich to ignite. This actually permits the storage and transportation of liquid fuels that have low boiling points in a safe manner by simply maintaining the gaseous gap of the storage containers beyond the rich flammability limit. It should be noted however that drops in temperature or unexpected leaning of the mixture by added oxygen may result in the unwanted ignition of the gases in the container with the subsequent risk of an explosion. Also, in the case of blended fuels the most volatile components may evaporate first, with the remaining heavier components requiring higher temperatures to evaporate, thus it is possible that if there is leakage of the more volatile components as the fuel ages the mixture above the liquid surface may get into the flammable limits and ignite, or even become too lean to ignite.

\section{Solid Fuels}

The ignition characteristics of solid fuels is very similar to those of liquid fuels except for the fact that gasifying a solid material is in general a more complex process that that of a liquid. Most combustible materials have a polymeric structure and the gasification occurs through a pyrolysis process rather than a change of phase process. The material pyrolysis process can be complicated with several intermediate pyrolysis steps, sometimes melting, and complex transport processes of the gaseous pyrolyzate through the material as it travels toward the surface [21]. Assuming that the pyrolysis process is described by a single, first-order in fuel, Arrhenius-type reaction, the rate of material gasification, or pyrolyzate, is given by the equation

$\dot{m}_{p y r}^{\prime \prime}=\int_{0}^{\delta} \dot{\omega}_{p y r}^{\prime \prime \prime} d x=\int_{0}^{\delta} \rho A Y_{F} \exp \left(-\frac{E}{R T}\right) d x$

It is interesting to note that although both the change of phase and pyrolysis processes are quite different, the characteristics of Eqs. 9 and 14 are somewhat similar, with the characteristics of the gasification process dependent exponentially on the inverse of the material temperature.

An important result of Eq. 14 is that since most practical materials have a relatively large activation energy the mass rate of pyrolyzate is strongly dependent on the material temperature. As a consequence, the mass rate of pyrolyzate is small until a certain temperature is reached. Since this temperature basically determines the initiation of material gasification, it can be viewed as an 'ignition temperature', similar to the evaporation temperature for liquid fuels. However, here also the pyrolysis of the material is only a necessary condition for ignition but not sufficient. For ignition to occur a flammable gaseous mixture must 
be reached near the location of the pilot. Similar issues related to layering of the gaseous mixture, concentration gradients and quenching by heat losses to the solid fuel also apply here.

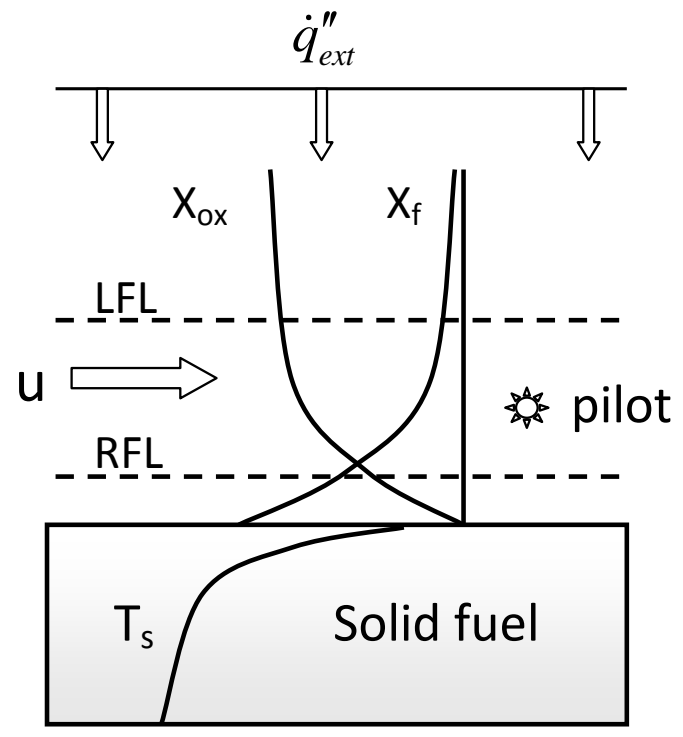

Fig. 5. Solid fuel piloted ignition.

The heating of the solid is given by the energy equation including in-depth pyrolysis. However, because of the strong dependence of the pyrolyzate rate on temperature, the solid material does not pyrolyze until its temperature reaches values close to the 'pyrolysis temperature'. Furthermore if the solid is being heated at the solid/gas interface, as normally occurs in practical cases, the maximum temperature will occur very near the surface (Fig. 5). For this reason it is reasonable to assume that material pyrolysis occurs at the surface. Then the energy equation in the solid is reduced to

$\rho c \frac{\partial T}{\partial T}=\frac{\partial}{\partial x}\left(k \frac{\partial T}{\partial x}\right)$

with boundary conditions $\left.T\right|_{l}=T_{0}$ and $-k \partial T /\left.\partial x\right|_{x=0}=\dot{q}_{\text {ext }}^{\prime \prime}$, with $\dot{q}_{\text {ext }}^{\prime \prime}$ being a convective and/or radiant surface heat flux. The rate of fuel pyrolysis could then be calculated through the surface energy balance

$\dot{m}_{p y r}^{\prime \prime}=\frac{\dot{q}_{e x t}^{\prime \prime}}{L_{p}}$

It should be noted that this simplified view of the pyrolysis process applies better to simple materials (thermoplastics for example) and that it is only approximately applicable to charring solids where pyrolysis occurs in-depth.

Equation 15 can be used to calculate the spatial and temporal variation of the solid temperature. As explained above, the material pyrolysis occurs approximately at a given surface temperature that can be defined as the 'ignition temperature', and the time to reach this temperature can be defined as the 'ignition time'. This is actually the thermo-physics behind the ignition component of test methods such as the cone calorimeter and the LIFT apparatus. For a thermally-thick solid exposed to a constant, uniform surface heat flux with negligible heat losses, the solution of Eq. 15 gives for the time of ignition:

$t_{i g}=\frac{\pi}{4} k \rho c \frac{T_{i g}-T_{0}}{\dot{q}_{\text {ext }}^{\prime 2}-\dot{q}_{\text {loss }}^{\prime \prime 2}}$ 
This equation is used to develop 'flammability diagrams' of materials [22] such as Fig. 6. These diagrams are sometimes used to rank the fire risk of materials through properties such as the critical flux for ignition, or minimum external heat flux for ignition $\left(t_{i g} \sim \infty\right.$ or $\left.\dot{q}_{c r i t}^{\prime \prime 2}=\dot{q}_{l o s s}^{\prime 2}\right)$; the surface ignition temperature, $T_{i g}$; or the thermal inertia of the material $k \rho c$ [22].

It is worth noticing that the ignition component of tests such as the cone calorimeter and LIFT apparatus are for solid fuels the equivalent of the Cleveland cup test for liquid fuels. They are all based on heating the condensed fuel to the point that piloted ignition of the fuel occurs, and determine the ignition temperature of the condensed fuel. Because the pilot is highly energetic, chemical kinetics plays a minor role and the ignition process is controlled by transport processes both in the gas and condensed phases. One important difference is that the liquid fuel tests assume a uniform temperature in the liquid and the solid material tests consider the surface temperature. Of course the tests for solid materials also address other aspects of the solid heating process that are not so important in liquid fuels.

Although the above approach provides a powerful practical tool to characterize the ignition properties of materials, the initiation of fuel pyrolysis of the material is only a necessary condition for ignition but not a sufficient one. As with the liquid fuels, for ignition to occur a flammable gaseous mixture must be generated near the pilot location.

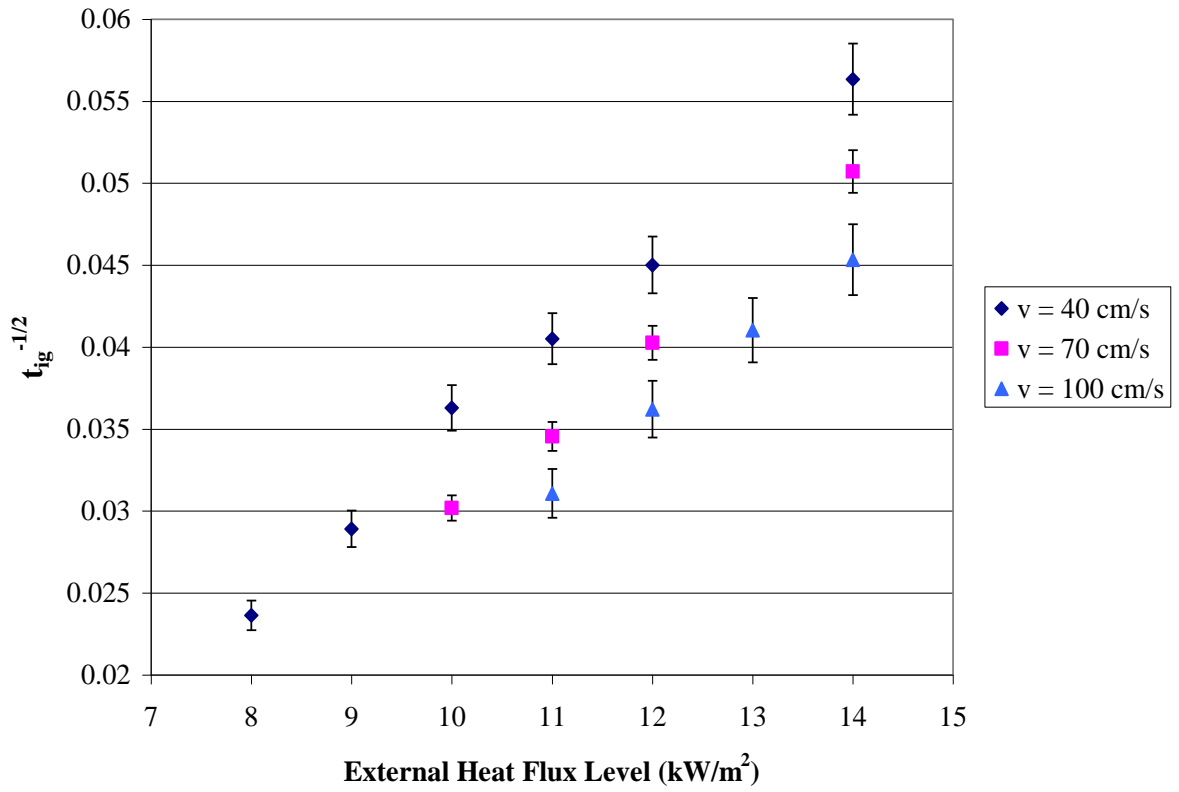

Fig. 6. Ignition delay time as a function of externally applied heat flux for several air flow velocities at an ambient pressure of $58.6 \mathrm{kPa}$.

Some researchers have gone beyond the concept of a 'surface ignition temperature' and proposed the more representative concept of a 'critical mass flux of pyrolyzate' for ignition to occur [10]. Recent experiments on this aspect of the problem show that this parameter is affected by the ambient conditions. An example is given by the results of Fig. 7. The determination of the critical mass flux of pyrolyzate at ignition provides a way to determine the conditions for ignition of solid combustibles that better reflects the mechanisms controlling the ignition process [10,23-25]. However, this parameter is more difficult to implement for practical purposes. 


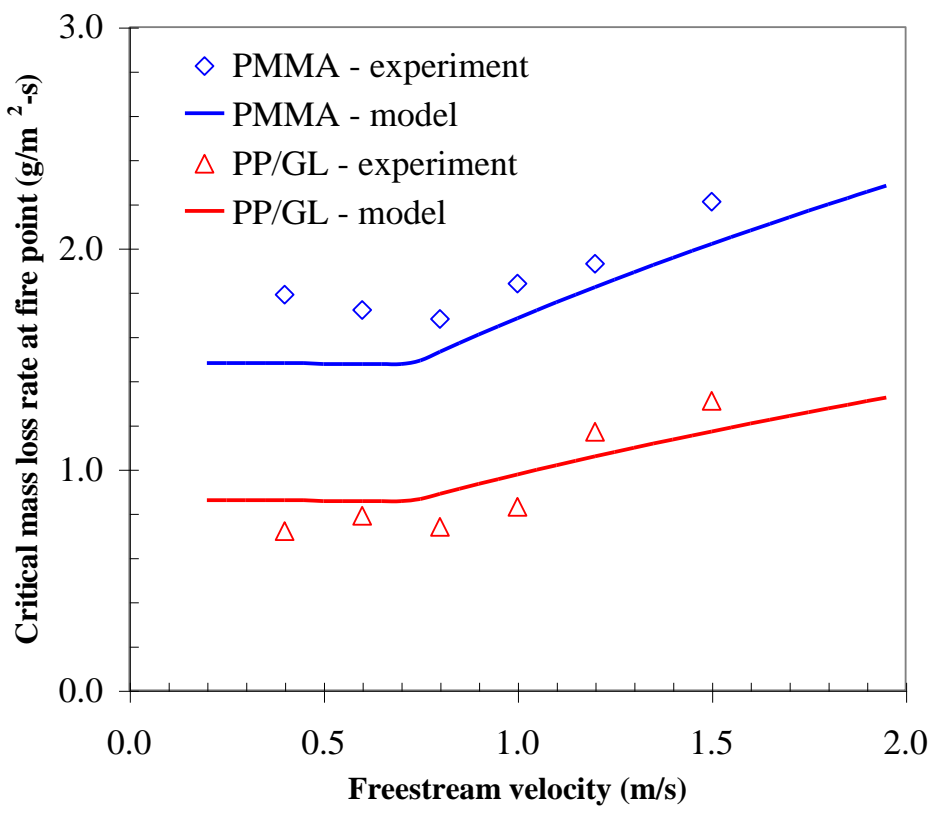

Fig. 7. Critical mass flux at the fire point.

The ambient conditions affect the onset of ignition both through the rate of pyrolyzate production and gas phase ignition. Particularly influential are the gas flow velocity around the combustible material, thermal radiation from or to adjacent sources, and the ambient pressure and oxygen concentration. Air currents affect ignition both by affecting the heating of the solid, the amount of pyrolyzate needed to attain a flammable mixture, and the energy needed for gas ignition by the pilot. Under external radiant heating increased air flows cause increased solid surface cooling by convection because the heat transfer coefficient will increase. Under convective heating however increased flow velocities will accelerate the solid heating. They will also affect the amount of pyrolyzate needed to attain a flammable mixture near the pilot, requiring larger amounts of pyrolyzate as the flow velocity is increased. They may also affect where the flammable mixture is located relative to the ignition source location and may deter ignition of the flammable gaseous mixture by convective cooling of the incipient reaction. Radiation from an adjacent radiant source (a fire for example) will accelerate the heating of the solid, although surface re-radiation cooling could decelerate it.

Ambient pressure will affect both the transport and chemical kinetic processes controlling ignition. Since decreasing pressure decreases the heat transfer coefficient, solids under radiation heating will heat up faster at low pressures because of the resulting lower heat losses. They will however heat up slower in hot convective flows. Ambient pressure will also affect the amount of pyrolyzate needed to reach a flammable mixture near the pilot through the oxidizer density, requiring less pyrolyzate as the pressure is decreased. As a result, as the ambient pressure is reduced, ignition of solid combustible materials exposed to radiant heating will ignite significantly faster both due to faster heating and less pyrolyzate needed for ignition. Recent experimental data show that ignition delays in high elevation locations such as Quito, Ecuador, could be $20 \%$ smaller than at sea level [24,25]. Of course, in addition, ambient pressure will affect the rate of the gas phase reaction (Eq. 3) and consequently the rate of heat release. If the ambient pressure is reduced significantly, chemical kinetic effects will eventually become dominant and the ignition process deterred, or even prevented. This is clearly reflected in the results of Fig. 8, where the different regimes of ignition are qualitatively estimated [25]. The presence of these regimes was also identified when comparing the different non-dimensional terms of the problem governing equations (gas phase ignition section). 


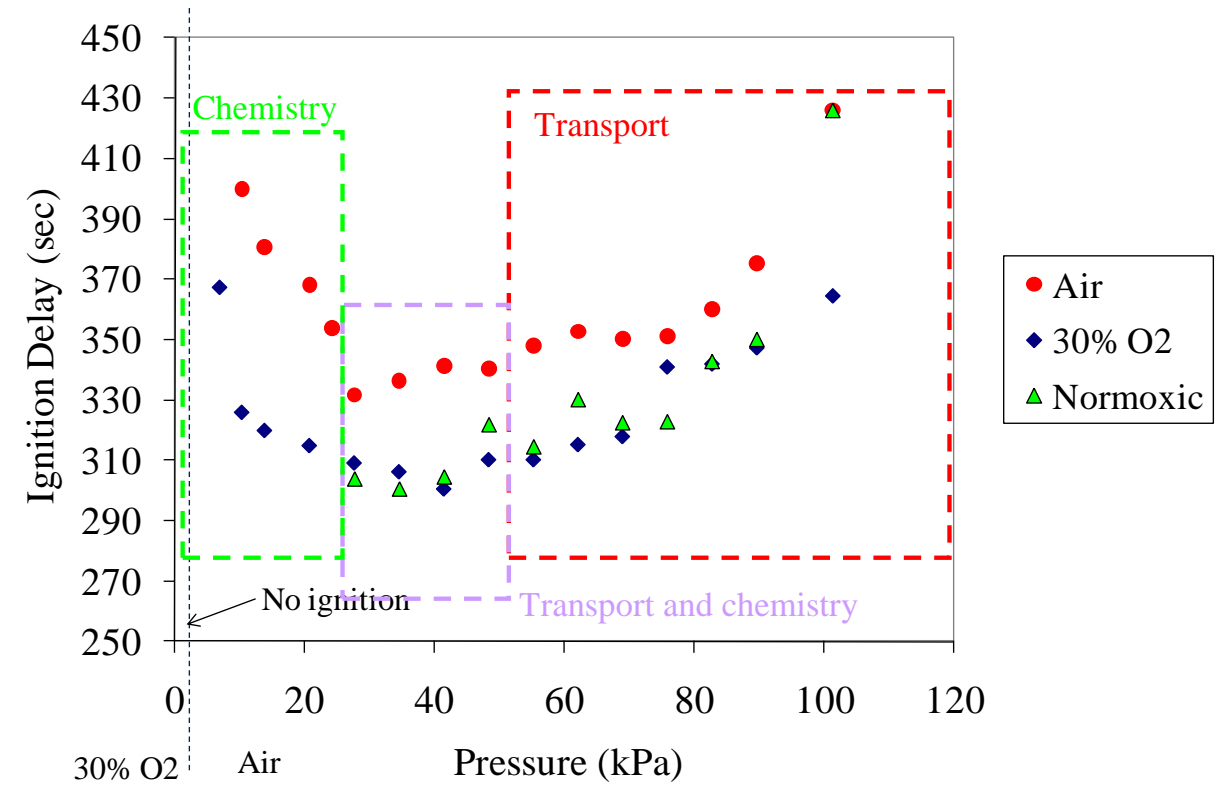

Fig. 8. Estimated regimes of ignition.

The ambient oxygen concentration and pressure will also affect the amount of pyrolyzate needed for ignition. Since the LFL is weakly dependent on oxygen concentration it does not greatly affect ignition near the LFL. The rate of the gas phase reaction and the rate of heat release is however strongly affected by the ambient oxygen concentration. Thus the ignition and eventual flame propagation will be enhanced by an increase in oxygen concentration $[8,25]$. The mass loss rate at ignition has been observed to decrease as the ambient pressure is reduced (Fig 9) [24]. This is attributed primarily to the easier attainment of a flammable mixture near the fuel surface and other effects such as the thickening of the mixing layer above the solid surface [24]. As the total pressure is reduced, the oxygen concentration is also reduced, and therefore less fuel vapor is needed to reach the lower flammability limit.

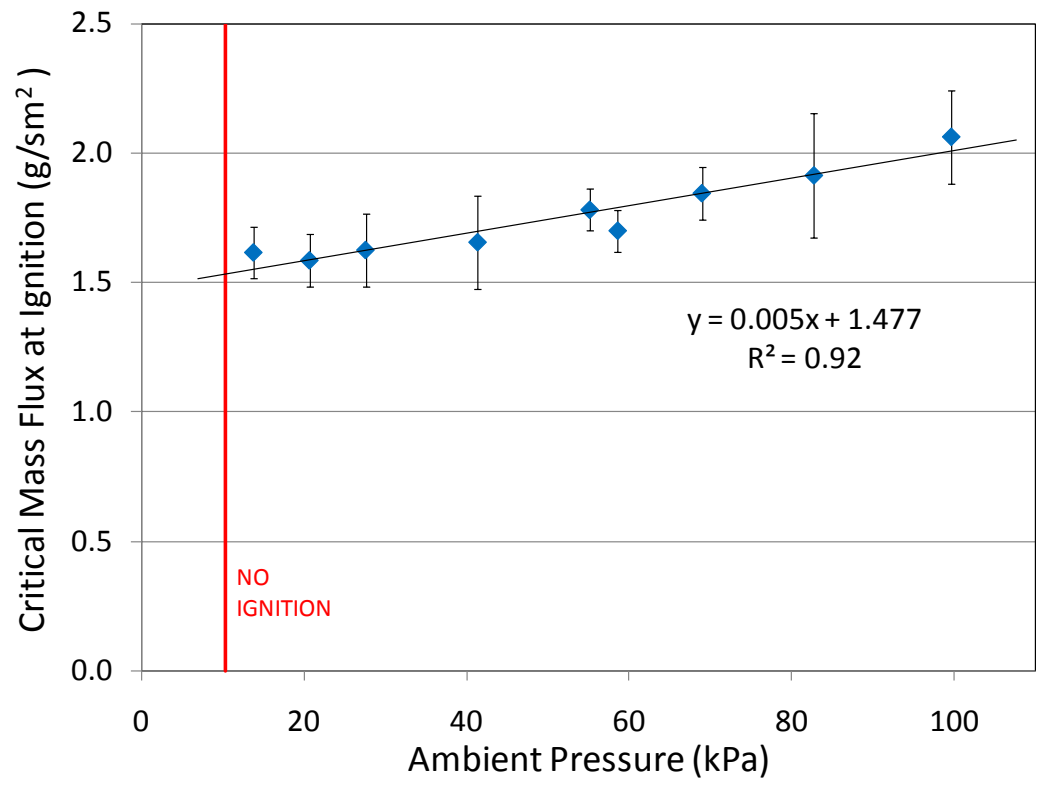

Fig. 9. Effect of pressure on the critical mass flux at ignition. 


\section{CONCLUDING REMARKS}

Often when looking at the ignition of condensed fuels, the emphasis is placed on searching for a condition in the solid or the liquid, generally a temperature that is associated with the ignition of the material. We have seen that this approach is sufficient for practical purposes, particularly when strong pilots in moderate ambient conditions are used to ignite the fuel vapor, so that gas phase ignition becomes secondary as a controlling mechanism. Also important is that any other method to determine ignition may be too complicated and therefore impractical. However, there is a need for awareness that any condition in the condensed phase is only a necessary condition for ignition but not a sufficient one. Eventually ignition is determined by the conditions in the gas phase, which are more or less common for all fuels. This fact should be understood when interpreting and implementing results from test methods that rely on condensed phase properties to determine the conditions for ignition.

\section{ACKNOWLEDGEMENT}

I would like to acknowledge the comments on this work from C. Lautenberger, D. Rich, S. Fereres and N. Alvares. The work of the author was supported by the Almy C. Maynard and Agnes Offield Maynard Endowed Chair of Mechanical Engineering at the University of California Berkeley.

\section{REFERENCES}

[1] Williams, F.A., Combustion Theory, Benjamin/Cummings, Menlo Park, CA, ISBN 0201407779, 1985.

[2] Glassman, I., Combustion, Academic Press, New York, ISBN 0122858506, 1977.

[3] Turns, S.R., An Introduction to Combustion (2 ${ }^{\text {nd }}$ ed.), McGraw Hill, New York, ISBN $0071260722,2000$.

[4] Law, C.K., Combustion Physics, Cambridge University Press, 2006, http://dx.doi.org/10.1017/CBO9780511754517

[5] Babrauskas, V., Ignition Handbook, Fire Science Publishers/Society of Fire Protection Engineers, Issaquah WA, 2003.

[6] Kanury, A.M., "Ignition of Liquid Fuels" The SFPE Handbook of Fire Protection Engineering, DiNenno P.J. (ed.), National Fire Protection Association, Quincy, MA, 1988, p. 1/20.

[7] Kanury, A.M., "Flaming Ignition of Solid Fuels" The SFPE Handbook of Fire Protection Engineering, DiNenno P.J. (ed.), National Fire Protection Association, Quincy, MA, 1988, p. 1/21.

[8] Fernandez-Pello, A.C., "The Solid Phase", Combustion Fundamentals of Fire, Cox, G. (ed.), Academic Press, 31-100, ISBN 0121942309, 1994.

[9] Atreya, A., (1998). "Ignition of Fires," Phil. Trans. Royal Soc. London, A 356: 2787-2813, http://www.jstor.org/stable/55049

[10] Drysdale, D.D., Introduction to Fire Dynamics (2 $2^{\text {nd }}$ ed.), Wiley, Chichester, 1999.

[11] Quintiere, J.G., Fundamentals of Fire Phenomena, Wiley, ISBN 0470091134, 2006, http://dx.doi.org/10.1002/0470091150

[12] Torero, J.L., "Flaming Ignition of Solids Fuels", The SFPE Handbook of Fire Protection Engineering ( $\left.4^{\text {th }} e d.\right)$, DiNenno P.J. (ed.), National Fire Protection Association, Quincy, MA, 2008, p. 2/11.

[13] Standard Method for Heat and Visible Smoke Release rates for Materials and Products Using Oxygen (ASTM E 1354), American Society for Testing Materials, Philadelphia, 1990.

[14] Standard Method for Determining Material Ignition and Flame Spread Properties (ASTM E 1321), American Society for Testing Materials, Philadelphia, 1990. 
[15] Amos, B. and Fernandez-Pello, A.C., (1988) Model of the Ignition and Flame Development on a Vaporizing Combustible Surface in a Stagnation Point Flow: Ignition by Vapor Fuel Radiation Absorption, Combustion Science and Technology, 62: 331-343, http://dx.doi.org/10.1080/00102208808924017

[16] Spalding, D.B., Some Fundamentals of Combustion, Butterworth, London, 1955.

[17] Munoz-Candelario, R. and Alvares, N.J., (1984) Definition of the Concentration Gradient Above Flammable Liquids, ASTM/STP 882, Symp. Appl. Fire Sci. to Fire Eng., Denver, CO, June 26-27, http://dx.doi.org/10.1520/STP35307S

[18] Lunardini, V.J., Heat Transfer in Cold Climates, Van Nostrand Reinhold Co., New York, NY, 1981.

[19] Standard Method for Flash and Fire Points by the Cleveland Open Cup Tester (ASTM D92-05a), American Society for Testing Materials, Philadelphia, 2010.

[20] Standard Method for Flash and Fire Points by the Pensky-Martens Closed Cup Tester (ASTM D93), American Society for Testing Materials, Philadelphia, 2010.

[21] Lautenberger, C. and Fernandez-Pello, A.C., Gpyro, http://code.google.com/p/gpyro/

[22] Quintiere, J.Q., (1981) A Simplified Theory for Generalizing Results from a Radiant Panel Rate of Flame Spread Apparatus, Fire and Materials, 5: 52, http://dx.doi.org/10.1002/fam.810050204

[23] Rich, D., Lautenberger, C., Torero, J.L., Quintiere, J.Q. and Fernandez-Pello, A.C., (2007) "Mass Flux Rate of Combustible Solids at Piloted Ignition," Proceedings of the Combustion Institute, 31(2): 2653-2660, http://dx.doi.org/10.1016/j.proci.2006.08.055

[24] Fereres, S., Lautenberger, C., Fernandez-Pello, C., Urban, D. and Ruff, G. (2011) Mass Loss Rate at Ignition in Reduced Pressure Environments, Combustion and Flame, http://dx.doi.org/10.1016/j.combustflame.2010.11.013

[25] McAllister, S., Fernandez-Pello, A.C., Ruff, G. and Urban, D. (2010) Effect of Pressure and Oxygen Concentration on Piloted Ignition Delay of Combustible Solids, Combustion and Flame, 157: 1753-1759, http://dx.doi.org/10.1016/j.combustflame.2010.02.022 